\title{
Pembinaan Usaha Kecil Mikro dan Menengah (UMKM) Konveksi Desa Karobelah Kecamatan Mojoagung - Jombang
}

\author{
Deni Widyo Prasetyo \\ deni.stiedw@gmail.com
}

STIE PGRI Dewantara Jombang

\begin{abstract}
abstrak
Perguruan tinggi sebagai bagian dari masyarakat, diharapkan kontribusinya secara nyata di masyarakat. Hal ini tertuang dalam bentuk Tri Dharma Perguruan Tinggi, yaitu Pendidikan/Pengajaran, Penelitian dan Pengabdian kepada masyarakat. Maka, sesuai dengan tugas yang harus dilakukan dosen, penulis melakukan bentuk pengabdian kepada masyarakat berupa pembinaan kepada kelompok usaha mikro, kecil dan menengah (UMKM) yang bergerak di desa Karobelah, Kecamatan Mojoagung, Kabupaten Jombang yang bergerak di bidang konveksi busana wanita, muslim dan anak-anak. Bentuk pembinaan yang dilakukan adalah dengan membantu pengurusan perijinan kepada instansi pemerintah (Dinas Perijinan), pembuatan logo perusahaan serta pemasaran secara online.Dari hasil kegiatan yang telah dilakukan oleh penulis, beberapa kelompok usaha konveksi telah mengursu ijin usaha resmi dan telah dibantu dan dikenalkan dengan sistim pemasaran secara online
\end{abstract}

Kata kunci: Pembinaan, UMKM, Konveksi, Karo Belah

abstract

College as a part of society, expected contribution in society. This is stated in the form of Tri Dharma Perguruan Tinggi, namely Education / Teaching, Research and Community Service. So, in accordance with the tasks that should be done lecturers, the authors make a form of community service in the form of coaching to groups of micro, small and medium enterprises (UMKM) engaged in the village Karobelah, District Mojoagung, Jombang regency engaged in female, children. The form of coaching is done by assisting the licensing of the government agencies (Office of Licensing), the creation of corporate logos and marketing online.Dari results of activities that have been done by the author, some groups of convection businesses have mengursu official business permission and have been assisted and introduced to the system marketing online

Keywords: Guidance, UMKM, Convection, Karo Belah

\section{A. PENDAHULUAN}

\section{Latar Belakang}

Salah satu tugas pemerintah sebagaimana yang diamanatkan oleh UUD 1945 adalah menciptakan masyarakat adil dan makmur secara merata. Hal ini dapat dimaknai bahwa upaya pemerintah untuk memeratakan pemberdayaan ekonominya harus menjangkau seluruh lapisan masyarakat hingga lapisan paling bawah yaitu masyarakat desa. Pemerintah dituntut untuk peka terhadap pembangunan ekonomi kerakyatan dengan berdasar pada kebudayaan, potensi dan kearifan lokal yang ada disetiap wilayah serta melibatkan wanita yang terbukti mampu menyokong perekonomian masyarakat lewat kontribusinya pada pemberdayaan ekonomi keluarga (Mutiarni, R, 2017)

Maka salah satu usaha yang bisa dilakukan pemerintah adalah dengan memberdayakan ekonomi kerakyatan dengan menggiatkan usaha mikro, kecil dan menengah (UMKM) dengan melibatkan berbagai pihak, antara lain dengan menggandeng perguruan tinggi.

Pemberdayaan dan pengembangan Usaha Mikro, Kecil dan Menengah (UMKM) merupakan upaya yang ditempuh pemerintah untuk mengatasi masalah pengangguran dan kemiskinan. Menurut Rudjito (2003) usaha mikro adalah usaha yang dimiliki dan dijalankan oleh penduduk miskin atau mendekati miskin. Usaha mikro sering disebut 
dengan usaha rumah tangga. Besarnya kredit yang dapat diterima oleh usaha adalah Rp 50 juta. Usaha mikro adalah usaha produktif secara individu atau tergabung dalam koperasi dengan hasil penjualan Rp 100 juta.

Sekolah Tinggi Ilmu Ekonomi (STIE) PGRI Dewantara Jombang, sebagai salah satu perguruan tinggi terkemuka di kabupaten Jombang berupaya memberikan kontribusi nyata terhadap UMKM di Kabupaten Jombang, antara lain dalam bentuk pembinaan dan pendampingan di desa Karobelah yang terletak di kecamatan Mojoagung, Jombang, khususnya UMKM konveksi busana muslim, wanita dan anak yang menjadi icon di desa Karobelah. Kelompok ibu-ibu rumah tangga di desa Karobelah telah mampu menjadi pilar penggerak ekonomi yang mampu memberikan kontribusi yang nyata terhadap ekonomi keluarga dan lingkungannya.

\section{Profil Mitra}

Desa Karobelah berada di Kecamatan Mojoagung, Kabupaten Jombang, Jawa Timur, dengan kode desa 3517062015. Luas wilayah Desa Karobelah seluas 211.517 Ha. Koordinat Bujur 112.34441 dan Koordinat Lintang -7.542519 . Desa Karobelah berada di ketinggian 35 meter diatas laut.

UMKM di Desa Karobelah cukup banyak, terutama untuk usaha Konveksi. Ada 5 kelompok usaha konveksi dengan skala mikro ( 3 buah) dan kecil ( 2 buah), dengan omzet rerata 2 (dua) kodi. Pemasaran usaha dilakukan di sekitar desa Karobelah yang dekat dengan pasar Mojoagung hingga ke luar kota. Mayoritas pemasaran yang dilakukan masih offline yaitu mengandalkan toko/ warung disekitar lokai usaha/pasar, tengkulak namun ada juga yang menggunakan media sosial.

Untuk kegiatan pengabdian kepada masyarakat, penulis memfokuskan kegiatannya pada salah satu pemilik konveksi Ibu Nur Aini yang bersedia menjadi mitra binaan. Selama ini, mitra binaan tidak memilki label khusus untuk produksinya. Ibu Nur Aini membuat baju berdasarkan pesanan dari pedagang besar/tengkulak yang memasarkan barangnya ke Surabaya.

Usaha konveksi Ibu Nur Aini belum memiliki ijin usaha dari dinas perindustrian dan perdagangan. Karena itu, penulis berupaya membantu ibu Nur Aini agar bisa mengurus ijin usahanya, mendesain logo perusahaan dan memberikan pelatihan pemasaran daring (online).

\section{B. Tinjauan Pustaka}

\section{Pengertian Usaha Kecil, Mikro dan Menengah}

Berdasarkan Undang-Undang Nomor 20 Tahun 2008 tentang Usaha Mikro, Kecil dan Menengah dalam pasal 3 disebutkan bahwa usaha mikro bertujuan menumbuhkan dan mengembangkan usahanya dalam rangka membangun perekonomian nasional berdasarkan ekonomi yang berkeadilan.

Ada perbedaan tentang usaha mikro, kecil, dan menengah yaitu;

1. Usaha Mikro Berdasarkan Undang Undang Nomor 20 Tahun 2008 tentang UMKM (Usaha Menengah Kecil dan Mikro) adalah usaha produktif milik orang perorangan dan / atau badan usaha perorangan yang memenuhi kriteria Usaha Mikro sebagaimana diatur dalam Undang-Undang ini. 
2. Usaha Kecil adalah usaha ekonomi produktif yang berdiri sendiri, yang dilakukan oleh orang perorangan atau badan usaha yang bukan merupakan anak perusahaan atau bukan cabang perusahaan yang dimiliki, dikuasai, atau menjadi bagian baik langsung maupun tidak langsung dari usaha menengah atau usaha besar yang memenuhi kriteria Usaha Kecil sebagaimana dimaksud dalam Undang-Undang ini.

3. Usaha Menengah adalah usaha ekonomi produktif yang berdiri sendiri, yang dilakukan oleh orang perseorangan atau badan usaha yang bukan merupakan anak perusahaan atau cabang perusahaan yang dimiliki, dikuasai, atau menjadi bagian baik langsung maupun tidak langsung dengan Usaha Kecil atau usaha besar dengan jumlah kekayaan bersih atau hasil penjualan tahunan sebagaimana diatur dalam Undang-Undang ini.

4. Usaha mikro merupakan kegiatan usaha yang dapat memperluas lapangan pekerjaan serta memberikan pelayanan ekonomi secara luas kepada masyarakat dan dapat berperan dalam proses pemerataan dan peningkatan pendapatan masyarakat, mendorong pertumbuhan ekonomi, serta berperan mewujudkan stabilitas nasional. Selain itu, usaha mikro adalah salah satu pilar utama ekonomi nasional yang medapatkan kesempatan utama, dukungan, perlindungan serta pengembangan yang secara luas sebagai wujud pihak yang tegas kepada kelompok usaha ekonomi rakyat, tanpa harus mengabaikan peranan usaha besar dan badan usaha milik pemerintah.

5. Menurut Departemen Tenaga Kerja (Depnaker) usaha mikro adalah usaha yang memiliki kurang dari 5 orang tenaga kerja.

\section{Perbedaan omzet UMKM dan UKM}

Usaha Mikro : adalah usaha produktif milik orang perorangan dan/atau badan usaha perorangan yang memenuhi kriteria Usaha Mikro sebagaimana diatur dalam Undang-Undang ini. Kriteria asset: Maks. Rp 50 Juta, kriteria Omzet: Maks. Rp 300 juta rupiah.

Usaha Kecil : adalah usaha ekonomi produktif yang berdiri sendiri, yang dilakukan oleh orang perorangan atau badan usaha yang bukan merupakan anak perusahaan atau bukan cabang perusahaan yang dimiliki, dikuasai, atau menjadi bagian baik langsung maupun tidak langsung dari usaha menengah atau usaha besar yang memenuhi kriteria Usaha Kecil sebagaimana dimaksud dalam Undang-Undang ini. Kriteria asset: Rp 50 juta - Rp 500 juta, kriteria Omzet: Rp 300 juta - Rp 2,5 Miliar rupiah.

Usaha Menengah : adalah usaha ekonomi produktif yang berdiri sendiri, yang dilakukan oleh orang perseorangan atau badan usaha yang bukan merupakan anak perusahaan atau cabang perusahaan yang dimiliki, dikuasai, atau menjadi bagian baik langsung maupun tidak langsung dengan usaha Kecil atau usaha besar dengan jumlah kekayaan bersih atau hasil penjualan tahunan sebagaimana diatur dalam Undang-Undang ini. Kriteria asset: 500 juta - Rp 10 Miliar, kriteria Omzet: >Rp 2,5 Miliar - Rp 50 Miliar rupiah.

\section{Peraturan Tentang UMKM}

COMVICE, Vol 2 No 1, April 2018

http://ejournal.stiedewantara.ac.id/index.php/COMVICE/article/view/120 
Peraturan tentang UMKM yang ada di Indonesia adalah Surat edaran Bank Indonesia No.26/I/UKK tanggal 29 Mei 1993 perihal Kredit Usaha Kecil (KUK) adalah usaha yang memiliki total asset Rp 60 juta (enam ratus juta rupiah) tidak termasuk tanah atau rumah yang ditempati. Pengertian usaha kecil ini meliputi usaha perseorangan, badan usaha swasta dan koperasi, sepanjang asset yang dimiliki tidak melebihi nilai Rp 600 juta.

Menurut Departemen Perindustrian dan perdagangan, pengusaha kecil dan menengah adalah kelompok industri modern, industri tradisional, dan industri kerajinan, yang mempunyai investasi, modal untuk mesin-mesin dan peralatan sebesar Rp 70 juta ke bawah dengan resiko investasi modal/tenaga kerja $\mathrm{Rp} 625.000$ ke bawah dan usahanya dimiliki warga Negara Indonesia.

Berdasarkan perkembangan UKM di Indonesia Dibedakan Menjadi 4 Kriteria yaitu

1. Livelihood Activities, merupakan Usaha Kecil Menengah yang digunakan sebagai kesempatan kerja untuk mencari nafkah, yang lebih umum dikenal sebagai sektor informal. Contohnya adalah pedagang kaki lima.

2. Micro Enterprise, merupakan Usaha Kecil Menengah yang memiliki sifat pengrajin tetapi belum memiliki sifat kewirausahaan.

3. Small Dynamic Enterprise, merupakan Usaha Kecil Menengah yang telah memiliki jiwa kewirausahaan dan mampu menerima pekerjaan subkontrak dan ekspor

4. Fast Moving Enterprise, merupakam Usaha Kecil Menengah yang telah memiliki jiwa kewirausahaan dan akan melakukan transformasi menjadi Usaha Besar (UB).

\section{Metode Pelaksanaan Kegiatan}

Kegiatan pengabdian kepada masyarakat yang dilakukan oleh penulis berupa pembinaan pemasaran secara daring (online) dan pengurusan perijinan di dinas perindustrian perdagangan kabupaten Jombang. Kegiatan pembinaan kepada mitra binaan di Desa Karobelah dilakukan selama bulan Pebruari 2018, berupa kunjungan resmi dan konsultasi via telepon.

\section{Hasil Kegiatan}

Pembinaan dilakukan secara intensif selama satu bulan yaitu bulan Pebruari 2018. Pada kunjungan pertama, penulis Memetakan sebaran kelompok usaha konveksi di desa Karobelah. Dari hail observasi tersebut, diketahui bahwa Terdapat 5 (lima) kelompok usaha konveksi di desa Karobelah, yang terdiri dari 2 (dua) usaha kecil dan 3 usaha mikro. Selanjutnya, penulis berkonsentrasi dengan memberikan pembinaan pada 1 (satu) pelaku usaha mikro yang bersedia untuk menjadi mitra binaan yaitu usaha konveksi Ibu Nur Aini dengan nama usahanya UD Putri Diana

Selanjutnya, Mitra binaan berkonsultasi kepada penulis tentang permsalahan yang dialami yaitu:

1. Belum mempunyai ijin usaha

2. Pemasaran masih terbatas, mengandalkan penjualan kepada pemilik usaha yang lebih besar yang menjadi tengkulak. 

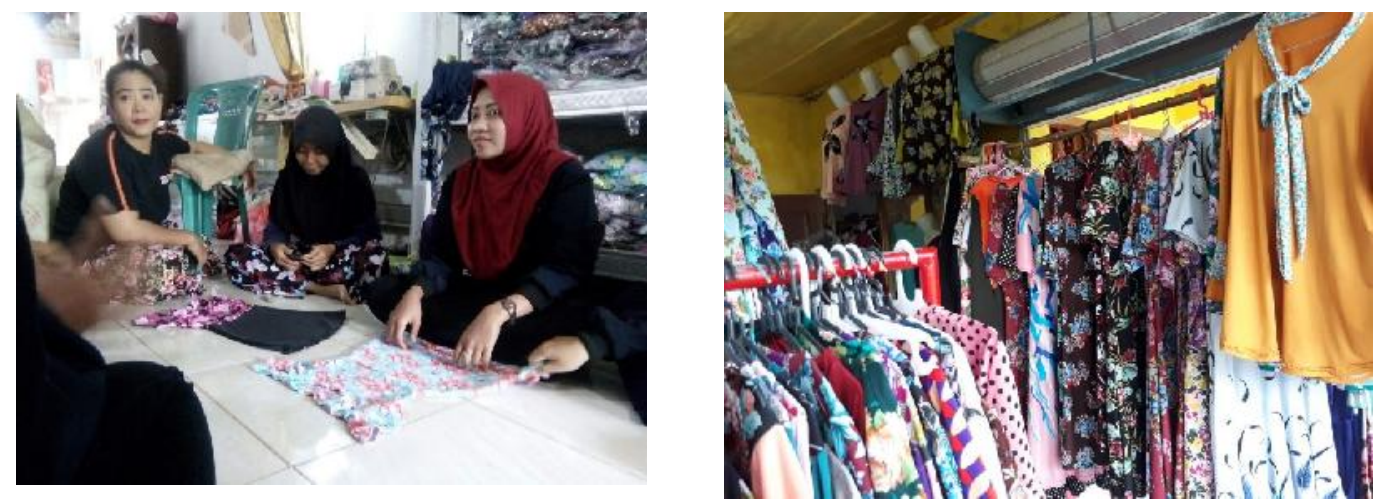

Gambar 1: Ibu Nur Aini dan Usaha Konveksi UD Putri Diana

Melihat dari permasalahan yang dihadapi mitra binaan, maka penulis membantu memberikan solusi. Langkah pertama adalah: penulis dengan dibantu mahasiswa membantu mendesaian logo usaha sebagai salah satu syarat agar bisa mendaftar ijin usaha ke dinas terkait.

Selain itu, mitra binaan juga belajar tentang pemasaran daring (online). Penulis dengan dibantu mahasiswa mengenalkan tentang pemasaran online sederhana menggunakan perangkat smartphone. Mitra binaan langsung mengaplikasikan proses penjualan secara daring di media Jombang Kuliner (Jokul) setiap hari rabu. Respon yang didapat cukup baik, karena langsung mendapat tanggapan dari pembeli untuk produk jilbab instan. Selain itu, penulis juga membantu pencatatan transaksi keuangan untuk mempermudah pengecekan keuangan usaha, karena dengan melihat dari laporan keuangan, akan diketahui posisi/kesehatan keuangan perusahaan (Mutiarni, R., Utomo, L. P., \& Zuhroh, S. ,2017).
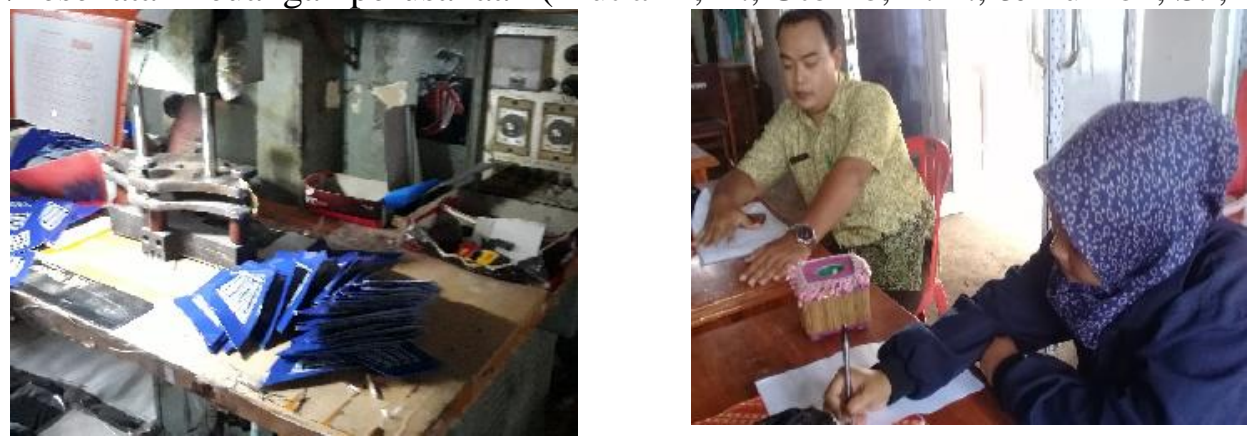

Gambar 2: Pendampingan Pembuatan Label Usaha dan Pelatihan pemasaran secara daring

\section{E. Penutup}

Dari hasil pembinaan yang telah dilakukan, dapat disimpulkan bahwa meskipun di Desa Karobelah yang terletak tidak jauh dari pusat kota Jombang, tetapi kelompok UMKM yang bergerak di bidang fashion (busana wanita) masih belum memanfaatkan teknologi untuk penjualan secara daring (online) untuk memperluas wilayah pemasaran. Sistim pemasaran selama ini masih mengandalkan pemasaran konvensional. Kelompok usaha mikro melakukan menjual hasil usahanya kepada tengkulak dan sebagian kecil dijual eceran di toko-toko baju sekitar. Selain itu, belum adanya ijin usaha secara resmi juga menjadi kendala bagi pengusaha untuk memperluas usahanya.

Untuk itulah, penulis memusatkan pembinaannya kepada pengurusan perijinan dan pemasaran daring (online) kepada mitra binaan. Di akhir kegiatan, mitra binaan telah melakukan pengurusan kepada mitra binaan dan mengajarkan tentang sistim pemasaran daring (online)

COMVICE, Vol 2 No 1, April 2018

http://ejournal.stiedewantara.ac.id/index.php/COMVICE/article/view/120 
Dari Simpulan diatas maka disarankan kepada mitra binaan (Ibu Nur Aini) tetap berkonsultasi dengan penulis agar permasalahan-permasalahan yang muncul kedepan, bisa dicarikan solusinya. Kepada pemerintah Jombang, disarankan agar lebih memperhatikan sentra industri konveksi yang terletak di desa Karobelah agar menjadi sentra konveksi di Kabupaten Jombang. Pembinaan hendaknya dilakukan menyeluruh dan terpadu, sehingga sentra industri konveksi Karobelah bisa menjadi stimulus bagi anggota masyarakat lain di desa Karobelah untuk berwirausaha di bidang lain yang menyokong perekonomian di desa.

http://goukm.id

\section{DAFTAR PUSTAKA}

Linda, (2012). Analisis Dampak Kredit Mikro Terhadap Perkembangan Usaha Mikro Di Kota Semarang. Skripsi S1, Program Sarjana Fakultas Ekonomika dan Bisnis Universitas Diponegoro Tahun 2012

Undang Undang Nomor 20 Tahun 2008 tentang UMKM (Usaha Menengah Kecil dan Mikro)

Asyarie, M. (1997). Islam, etos kerja dan pemberdayaan ekonomi umat. Lesfi.

Priyanto, S. H. (2009). Mengembangkan pendidikan kewirausahaan di masyarakat. Jurnal PNFI, 1(1), 57-82.

Huka Gusadi, Meriyati., E Pandelaki, E., \& Setyowati, E. (2015). Penataan Sentra Industri Konveksi Dan Bordir Dukuh Krajan I Kabupaten Kudus (Doctoral dissertation, FAKULTAS TEKNIK UNDIP).

Meilani, M. T., \& Sutrisno, R. (2015, November). Model Disain Rencana Bisnis UKM Konveksi di Kabupaten Bandung. In Prosiding Industrial Research Workshop and National Seminar (Vol. 6, pp. 202-210).

Mutiarni, R., Utomo, L. P., \& Zuhroh, S. (2017). Pendampingan Pencatatan Transaksi Keuangan Pada Koperasi Bunga Harapan Desa Ceweng. Comvice: Journal of Community Service, 1(1), 33-38.

Mutiarni, R. (2017). Implementasi Electronic Data Processing Pada Koperasi Wanita. Eksis: Jurnal Riset Ekonomi dan Bisnis, 12(2 Okt), 135-148.

Rahmawati, D. I., \& Roesminingsih, M. V. (2016). Hubungan Pelaksanaan Pendidikan Kecakapan Hidup Pelatihan Menjahit Dalam Pemberdayaan Perempuan Dengan Motivasi Wirausaha. J+ Plus Unesa, 5(1).

Surat edaran Bank Indonesia No.26/I/UKK tanggal 29 Mei 1993 